\title{
Genetic and Biochemical Properties of Thialysine-resistant Mutants of Saccharomyces cerevisiae
}

\author{
By JOHN H. ZWOLSHEN AND J. K. BHATTACHARJEE* \\ Department of Microbiology, Miami University, Oxford, Ohio 45056, U.S.A.
}

(Received 18 April 1980; revised 22 July 1980)

\begin{abstract}
Three groups of lysine-excreting, thialysine-resistant mutants of Saccharomyces cerevisiae were derived from the wild-type strain (X2180) by mutagenic treatment and selected on the basis of a cross-feeding assay. Mutants MNNG2-9, MNNG2-27, MNNG2-39 and MNNG2-62 (group I) exhibited a 2:2 segregation for thialysine resistance following mating with a wild-type strain and a lower than wild-type lysyl-tRNA synthetase activity; the thialysine-resistant phenotype was dominant in specific hybrids. Mutant MNNG2-2 (group II) was similar to group I mutants except that the thialysine-resistant phenotype was recessive in the hybrid. Mutant MNNG3-142 (group III) exhibited an irregular ratio of segregation of thialysine resistance and a significantly lower lysyl-tRNA synthetase activity; the thialysineresistant phenotype was recessive in the hybrid. The growth of both group I and group III mutants was temperature-sensitive. The thialysine-resistant mutants exhibited pleiotropic properties including the increased production and excretion of lysine, thermosensitive growth and an impairment of lysyl-tRNA synthetase activity.
\end{abstract}

\section{INTRODUCTION}

Metabolite analogues have been used extensively to study the mechanism of regulation of the biosynthesis of amino acids in bacteria (Umbarger, 1971) and to a lesser extent in lower eukaryotic organisms including yeast (Delforge et al., 1975; Greer \& Fink, 1976; Hutter, 1979). Thialysine, an analogue of lysine, inhibits the growth of several micro-organisms including Saccharomyces cerevisiae (Coles \& Brenchley, 1976; Freidrich \& Demain, 1977; Haidaris \& Bhattacharjee, 1978). Thialysine-resistant mutants exhibit altered lysyl-tRNA synthetase activity in Escherichia coli (Hirschfield \& Zamechnik, 1971), altered regulation of lysine-sensitive aspartokinase in Bacillus subtilis and Salmonella typhimurium (Vold et al., 1975; Jegede et al., 1976) and an increased production and excretion of lysine in Brevibacterium flavum, Candida pelliculosa and S. cerevisiae (Sano \& Shiio, 1970; Takenouchi et al., 1977; Haidaris \& Bhattacharjee, 1978). Since most cereals are deficient in lysine, high lysine-excreting mutants of bacteria and yeast are of special interest in the production of lysine. Also, an increased production of lysine in such mutants would suggest an impairment of the normal regulation of the biosynthesis of lysine.

In yeast and other fungi there are fewer mutants available for the study of aminoacyl-tRNA synthetase than in bacteria (Neidhardt et al., 1975) and the role of specific aminoacyl-tRNA synthetases in the regulation of the biosynthesis of the corresponding amino acids is not well understood. Since the pathway for the biosynthesis of lysine in $S$. cerevisiae is completely different from the pathway used by bacteria (Broquist \& Trupin, 1966; Bhattacharjee \& Sinha, 1972), the effects of thialysine-resistant mutants on the biosynthesis of lysine in this organism are of special interest. We report here for the first time the genetic and biochemical properties of some lysine-excreting, thialysine-resistant mutants of $S$. cerevisiae. 


\section{METHODS}

Strains. Wild-type strains X2180-1A (a $t h l$ ) (courtesy of Dr R. K. Chan) and $609(\alpha t h l)$ (courtesy of Dr C. C. Lindegren), lysine-producing thialysine-resistant mutants of Saccharomyces cerevisiae (Table 1), and a lysine auxotroph lys 3 of Rhodotorula glutinis MU-1 (Kinzel \& Bhattacharjee, 1979) were used.

Media and growth conditions. Nutrient medium (Gray \& Bhattacharjee, 1976) was used for the growth of colonies after mutagenic treatment and to maintain stock cultures. Minimal medium was used for the selection of lysine-producing mutants. Minimal agar medium (containing: Difco yeast nitrogen base without amino acids and ammonium sulphate, $6.7 \mathrm{~g}$; thialysine, $0.1 \mathrm{~g}$; glucose, $10 \mathrm{~g}$; proline, $0.5 \mathrm{~g}$; agar, $25 \mathrm{~g}$; distilled water. to $1 \mathrm{l}$ ) was used for the selection and maintenance of thialysine-resistant mutants. Sporulation medium was the same as that described by McClary et al. (1959). All cultures were incubated at $30^{\circ} \mathrm{C}$, unless otherwise indicated, and those in liquid medium were shaken.

Selection of lysine-excreting, thialysine-resistant mutants. Mutagenic treatment and the screening of thialysine-resistant mutants were performed according to procedures described previously (Haidaris \& Bhattacharjee, 1978), and the lysine-excreting mutants were selected on the basis of a cross-feeding assay. A lawn was prepared with $0.1 \mathrm{ml}$ suspension (about $1 \times 10^{5}$ cells $\mathrm{ml}^{-1}$ ) of $R$. glutinis lysine auxotroph lys 3 on each plate of minimal agar medium and the plates were incubated for several hours to allow the surface to dry. Six or seven thialysine-resistant mutants and the parent wild-type strain were then seeded on each plate and the plates were incubated for 5 to $10 \mathrm{~d}$. Thialysine-resistant mutants which supported growth of the $R$. glutinis lysine auxotroph by cross-feeding were selected as high lysine-producing, thialysine-resistant mutants (Fig. 1). Red colonies of $R$. glutinis lysine auxotroph resulted from the cross-feeding, thus eliminating any doubt as to the excess lysine-producing and lysine-excreting ability of the thialysine-resistant mutants.

Genetic analysis. Mating, sporulation, micromanipulation and tetrad analysis were performed according to standard procedures (Sherman \& Lawrence, 1974). Hybrids were prepared by mating each mutant with wild-type strain 609. The dominance of thialysine resistance was determined in diploid cells isolated by micromanipulation following mating of a thialysine-resistant mutant with wild-type strain 609 . Each colony from isolated single cells was examined for diploidy on the basis of the ability to sporulate in sporulation medium and for thialysine resistance by the ability to grow on thialysine-supplemented minimal agar medium.

Lysvl-tRNA synthetase activity. Cells from $62 \mathrm{~h}$ cultures were disrupted using a Bronwill MSK homogenizer (Bronwill Scientific Co., San Mateo, Calif., U.S.A.) (Gray \& Bhattacharjee, 1976). Cell extracts were dialysed against $100 \mathrm{vol} .0 .08 \mathrm{M}$-Tris/ $\mathrm{HCl}$ buffer $\mathrm{pH} 7.3$ in the cold for $18 \mathrm{~h}$ with three changes of buffer. Protein was determined by the biuret method using bovine serum albumin as a standard (Gornall et al., 1949). The reaction mixture for the assay of lysyl-tRNA synthetase [L-lysine:tRNA ${ }^{\text {Lys }}$ ligase (AMP-forming); EC 6.1.1.6] activity contained (in $1 \mathrm{ml}$ ): purified yeast tRNA (Sigma type $\mathrm{X}$ or type 1). 45 units: Tris/ $\mathrm{HCl}$ buffer $\mathrm{pH} 7 \cdot 3,80 \mu \mathrm{mol}$; $\mathrm{MgCl}_{2}, 7.5 \mu \mathrm{mol}$; ATP, $4 \mu \mathrm{mol}$; reduced glutathione, $3 \mu \mathrm{mol} ; \mathrm{L}-\left[\mathrm{U}^{14}{ }^{14} \mathrm{C} \mid l y s i n e, 2.56 \mathrm{nmol}\right.$; cell extract. equivalent to $2 \mathrm{mg}$ protein. The ATP was neutralized to $\mathrm{pH} 7.0$ with $\mathrm{KOH}$ before addition. The mixture was incubated in a water bath at $37^{\circ} \mathrm{C}$ for $15 \mathrm{~min}$ and the reaction was stopped by adding $4 \mathrm{ml}$ cold $5 \%(\mathrm{w} / \mathrm{v})$ trichloroacetic acid

Table 1. Strains of Saccharomyces cerevisiae*

$\begin{array}{lc}\quad \text { Strain } & \text { Genotype } \\ \text { X2180-1A } & \text { a } t h l \\ 609 & \text { a } t h l \\ \text { MNNG2-2 } & \text { a } T H L \\ \text { MNNG2-3 } & \text { a } T H L \\ \text { MNNG3-142 } & \text { a } T H L \\ \text { MNNG2-9 } & \text { a } T H L \\ \text { MNNG2-7 } & \text { a } T H L \\ \text { MNNG2-13 } & \text { a } T H L \\ \text { MNNG2-27 } & \text { a } T H L \\ \text { MNNG2-39 } & \text { a } T H L \\ \text { MNNG2-52 } & \text { a } T H L \\ \text { MNNG2-60 } & \text { a } T H L \\ \text { MNNG2-62 } & \text { a } T H L \\ \text { MNNG2-69 } & \text { a } T H L \\ \text { MNNG2-72 } & \text { a } T H L \\ \text { MNNG27-1-31 } & \alpha T H L \\ \text { MNNG27-1-12 } & \alpha T H L \\ \text { MNNG27-31-9-17 } & \alpha T H L\end{array}$

* Thialysine-resistant $(T H L)$ strains were developed in this project. Sources of the wild-type strains (X2180-1A and 609) are given in Methods. 
and keeping the tube in ice for $10 \mathrm{~min}$. The reaction mixture was filtered through a cellulose filter $(0.45 \mu \mathrm{m}$ pore diarn.). The filters were washed three times with $4 \mathrm{ml}$ cold trichloroacetic acid solution. The radioactivity associated with each filter was measured using a toluene/ethanol scintillation fluid in a Beckman LS100 liquid scintillation spectrometer. The control lacked ATP.

Chemicals. Fine chemicals were from Sigma, media were from Difco, $\mathrm{L}-\left[\mathrm{U}-{ }^{14} \mathrm{C}\right]$ lysine was from ICN Chemical \& Radioisotope (Irvine, Calif., U.S.A.) and glusulase was from Endo Laboratories (Garden City, N.Y., U.S.A.).

\section{RES ULTS}

\section{Lysine-producing, thialysine-resistant mutants}

After mutagenic treatment of wild-type strain X2180-1A with $N$-methyl- $N^{\prime}$-nitro- $N$ nitrosoguanidine, 14450 colonies were examined of which 418 were thialysine-resistant. A total of 37 high lysine-producing, thialysine-resistant colonies were selected on the basis of the cross-feeding assay (Fig. 1). Chemical and microbiological assays were used for the determination of lysine. Each of these mutants produced at least $100 \mu \mathrm{g}$ lysine per ml culture. Wild-type cells neither accumulate lysine in the intracellular pool nor excrete any significant amount of lysine compared with the mutant strains (Haidaris \& Bhattacharjee, 1978).

\section{Determination of the segregation ratio for selected thialysine-resistant mutants}

To determine whether or not the thialysine-resistant phenotype of the lysine-producing mutants was due to the mutation of a single nuclear gene, tetrads from individual hybrids between specific mutants and wild-type strain $609(\alpha, t h l)$ were analysed (Table 2$)$. Five of the mutants (MNNG2-2, MNNG2-9, MNNG2-27, MNNG2-39 and MNNG2-62) exhibited 2:2 segregation for thialysine resistance and mating-type. Two of these mutants (MNNG2-9 and MNNG2-39) exhibited one tetrad each with a $3: 1$ segregation for thialysine resistance. Tetrad distributions between the mating-type locus and thialysine resistance indicated no significant trend for any type of linkage. Highly irregular segregation was observed for thialysine resistance in all tetrads from hybrids between mutants MNNG2-3 and MNNG3-142 with strain 609. A second generation backcross of mutant MNNG3-142 also

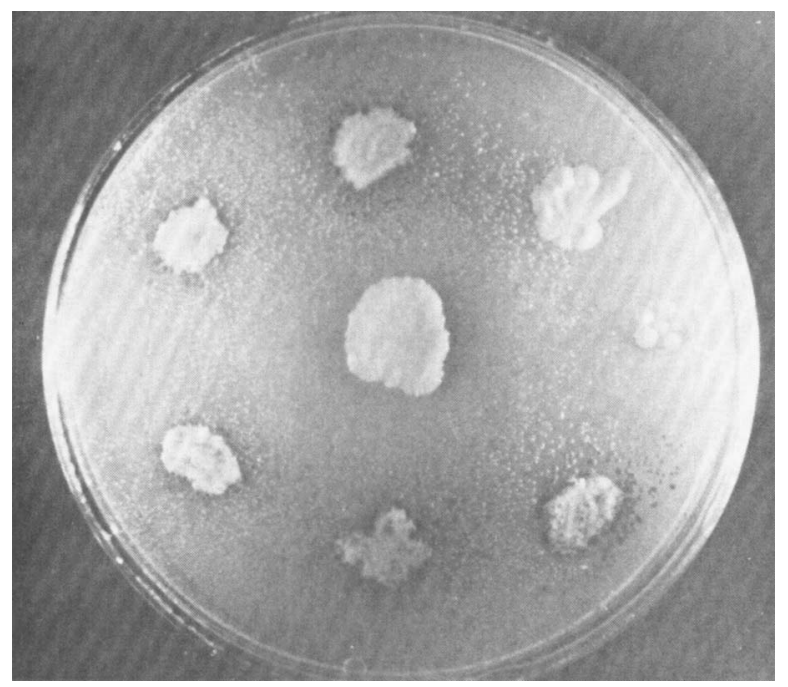

Fig. 1. Selection of lysine-excreting, thialysine-resistant mutants on the basis of cross-feeding assay. A lawn of $R$. glutinis lysine auxotroph lys 3 was prepared on a minimal agar plate and seven thialysine-resistant mutants and the wild-type strain X2180-1A (negative control in the centre of the plate) were seeded on to the agar surface. After several days of incubation, high lysine-producing mutants were selected on the basis of their ability to support the growth of the $R$. glutinis lysine auxotroph (small colonies). 
Table 2. Determination of the segregation ratio of the mating type and thialysine resistance and the tetrad distributions

\begin{tabular}{lcccccr} 
Hybrid & $\overbrace{T H L: t h l}$ & $\alpha: \mathbf{a}$ & $\begin{array}{c}\text { Tetrads exhibiting } \\
2: 2 \text { segregation for } \\
\text { for } T H L: t h l\end{array}$ & \multicolumn{2}{c}{$\begin{array}{c}\text { Tetrad distributions* } \\
\text { for a-THL }\end{array}$} \\
$(\mathbf{a} T H L) \times 609(\alpha t h l)$ & 10 & 10 & 0 & 1 & 0 & NPD \\
$(\mathbf{a} T H L) \times 609(\alpha t h l)$ & 16 & 17 & $1(3: 1)$ & 3 & 4 & 10 \\
$7(\mathbf{a} T H L) \times 609(\alpha t h l)$ & 16 & 16 & 0 & 2 & 3 & 11 \\
$9(\mathbf{a} T H L) \times 609(\alpha t h l)$ & 19 & 20 & $1(3: 1)$ & 4 & 5 & 11 \\
$2(\mathbf{a} T H L) \times 609(\alpha t h l)$ & 13 & 13 & 0 & 1 & 3 & 9
\end{tabular}

* PD, Parental ditype; NPD, non-parental ditype; TT, tetratype.

Table 3. Determination of dominance or recessiveness of the thialysine-resistant phenotype for selected mutants

MNNG2-2 (a THL) $\times 609(\alpha t h l)$

MNNG2-9 (a THL) $\times 609(\alpha t h l)$

MNNG2-27 (a THL) $\times 609(\alpha$ thl $)$

MNNG2-39 (a THL) $\times 609(\alpha$ thl $)$

MNNG2-62 (a $T H L) \times 609(\alpha t h l)$

\section{No. of}

No. of
diploid isolates
Growth on
thialysine
medium

tested

$\begin{array}{cccc}\begin{array}{c}\text { diploid } \\ \text { solates } \\ \text { tested }\end{array} & \begin{array}{c}\text { Growth on } \\ \text { thialysine } \\ \text { medium }\end{array} & \begin{array}{c}\text { Sporulation } \\ \text { Recessive }\end{array} & \begin{array}{c}\text { Dominant } \\ \text { or } \\ \text { Recess. }\end{array} \\ 4 & + & + & \text { Dom. } \\ 2 & - & + & \text { Rec. } \\ 4 & - & + & \text { Rec. } \\ 5 & + & + & \text { Dom. } \\ 5 & + & + & \text { Dom. } \\ 5 & + & + & \text { Dom. }\end{array}$

MNNG2-9 (a THL) $\times 609(\alpha t h l)$

MNNG2-2 (a THL) $\times 609(\alpha \mathrm{thl})$

MNNG3-142 (a THL) $\times 609(\alpha t h l)$

MNNG2-27 (a THL) $\times 609(\alpha$ thl $)$

MNNG2-39 (a THL) $\times 609(\alpha$ thl $)$

MNNG2-62 (a THL) $\times 609(\alpha t h l)$

\section{Table 4. Recombination analyses among some thialysine-resistant mutants}

Hybrids were constructed between specific thialysine-resistant mutants. Viable segregants (tetrads and individual spores) were tested for the ability to grow in minimal medium and minimal medium containing thialysine.

\section{Hybrid}

MNNG2-2(a $T H L) \times 24 \mathrm{C}(\alpha T H L) \dagger$

MNNG2-62 (a THL) $\times 24 \mathrm{C}(\alpha T H L)$

MNNG2-27 (a THL) $\times 9 \mathrm{a}(\alpha T H L) \ddagger$

MNNG2-62 (a THL) $\times 9 \mathrm{a}(\alpha T H L)$

MNNG2-39 (a THL) $\times 9 \mathrm{a}(\alpha T H L)$
Tetrad

$\begin{array}{ccccc}\text { PD } & \text { NPD } & \text { TT } & \begin{array}{c}\text { Total } \\ \text { no. of } \\ \text { spores }\end{array} & \begin{array}{c}\text { No. of } \\ \text { spores } \\ \text { recombined }\end{array} \\ 6 & 3 & 7 & 177 & 37 \\ & & & 46 & 5 \\ 2 & 4 & 3 & 128 & 38 \\ 1 & 1 & 0 & 115 & 15 \\ & & & 129 & 28\end{array}$

* PD, Parental ditype; NPD, non-parental ditype; TT, tetratype.

$\dagger$ Segregant of MNNG2-9 (a THL) $\times 609(\alpha t h l)$.

$\ddagger$ Segregant of MNNG2-2 (a THL) $\times 609(\alpha t h l)$.

exhibited irregular segregations (results not shown). Several other mutants were not amenable to genetic analysis because of the lack of ability to mate and/or sporulate.

\section{Dominance or recessiveness of the thialysine-resistant phenotype}

Colonies from isolated single diploid cells of hybrids between wild-type strain 609 and mutants MNNG2-9, MNNG2-27, MNNG2-39, or MNNG2-62 grew on thialysinesupplemented minimal agar medium within $72 \mathrm{~h}$. These isolates also sporulated confirming their diploid state (Table 3). In the case of mutants MNNG2-2 and MNNG3-142, the isolated heterozygous diploids did not grow on thialysine-supplemented minimal agar medium. Ascospores from one of these diploids showed 12 thialysine-resistant and 11 thialysine- 
Table 5. Lysyl-tRNA synthetase activity of thialysine-resistant mutants

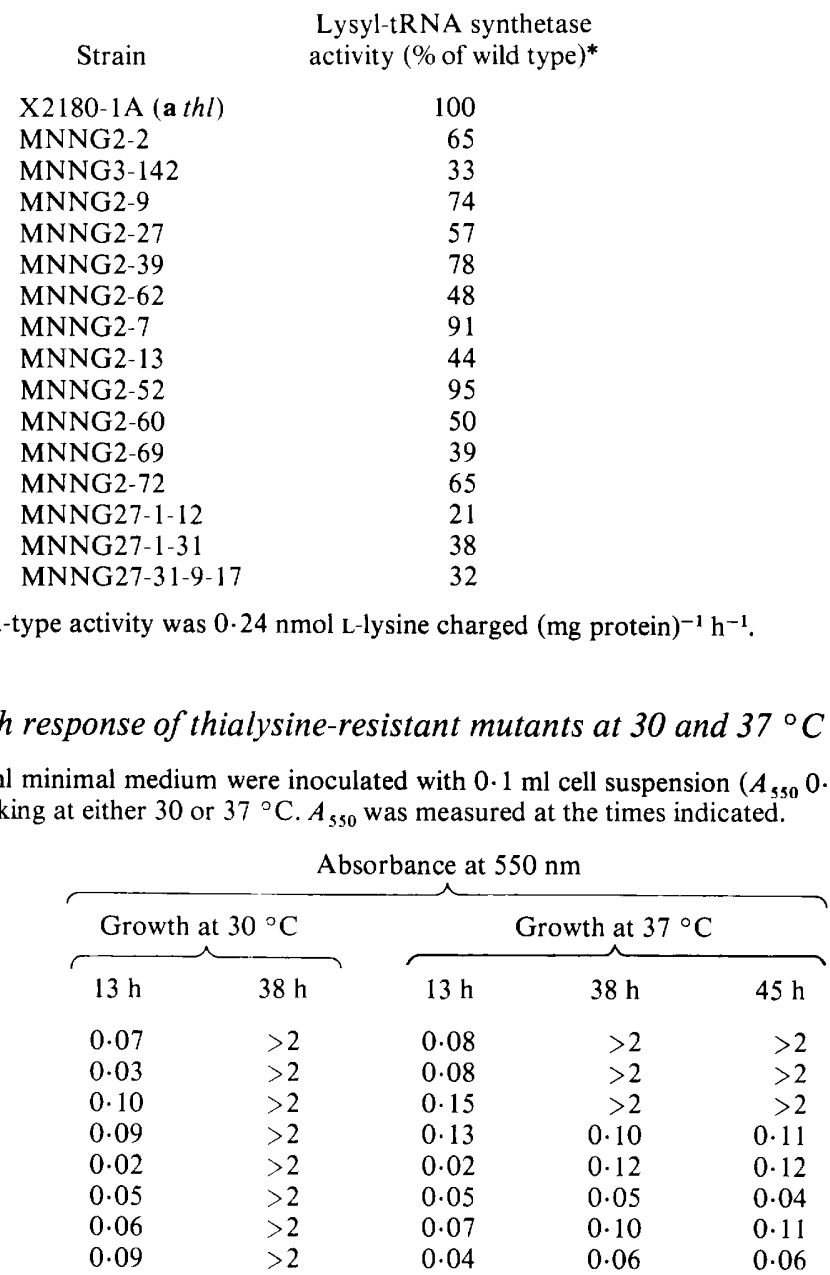

sensitive (1:1 ratio) segregants indicating the heterozygous nature of the isolated diploid cells.

Several crosses were made among the mutants or their progeny. Because of poor germination, conventional tetrad analysis for the determination of linkage among the mutants was not possible. Recombinants were obtained from a small number of tetrads and isolated single spores from all of the hybrids were tested (Table 4).

\section{Lysyl-tRNA synthetase activity in selected mutants}

The lysyl-tRNA synthetase activity was determined in a number of thialysine-resistant mutants: activities ranged between 21 and $95 \%$ of the wild-type activity (Table 5). Of the 15 mutants examined, seven showed less than $50 \%$ and seven more than $50 \%$ of the activity of the parent strain.

\section{Temperature sensitivity of thialysine-resistant mutants}

Several thialysine-resistant mutants were examined for their ability to grow at $37^{\circ} \mathrm{C}$ (Table 6). As expected, all of the mutants grew well at $30^{\circ} \mathrm{C}$, but only two mutants (MNNG2-2 and MNNG2-3) and the wild-type strain grew at $37^{\circ} \mathrm{C}$. The remaining mutants showed no significant growth at $37^{\circ} \mathrm{C}$ even after $45 \mathrm{~h}$. 


\section{DIS C USSION}

The ability of thialysine-resistant mutants to produce excess lysine per unit of culture compared with the wild-type strain is an indication that the regulation of the biosynthesis of lysine has been impaired in such mutants. Therefore, in an attempt to obtain possible regulatory mutants for the biosynthesis of lysine, only lysine-producing, thialysine-resistant mutants were isolated and used in this study for genetic and biochemical characterization. The majority of the thialysine-resistant mutants, however, did not produce lysine. Since the parent wild-type strain is sensitive to thialysine, it is assumed that mutants that did not excrete lysine were resistant to thialysine because of the inability to transport the analogue into the cells as a result of mutation (Umbarger, 1971). Some of these mutants may still, however, be regulatory mutants for the biosynthesis of lysine.

A 2:2 segregation for thialysine resistance in the tetrads demonstrates that the thialysine-resistant phenotype in each of the mutants MNNG2-2, MNNG2-9, MNNG2-27, MNNG2-39 and MNNG2-62 is the result of a single nuclear gene mutation. A $3: 1$ segregation for thialysine resistance in the case of mutants MNNG2-9 and MNNG2-39 can be explained on the basis of gene conversion (Lindegren, 1953; Mortimer \& Hawthorne, 1976). A predominantly $2: 2$ segregation with a low frequency of $3: 1$ or $1: 3$ segregation is commonly observed when a phenotype is due to a single nuclear gene mutation. An irregular segregation ratio for thialysine resistance indicates that the mutants MNNG2-3 and MNNG3-142 contain more than one nuclear gene mutation.

Results of the dominance test indicate that more than one gene is responsible for thialysine resistance in these mutants. This conclusion is based on the observation that four of the mutants (MNNG2-9, MNNG2-27, MNNG2-39 and MNNG2-62) express their resistance as dominant and two (MNNG2-2 and MNNG3-142) express their resistance as recessive. None of the mutants tested are linked to the mating-type locus based on the ratio of PD, NPD and TT tetrads. Two of the mutants (MNNG2-9 and MNNG2-39) may be linked to a centromere other than the one in chromosome III which contains the centromere-linked mating-type locus (Mortimer \& Hawthorne, 1976). Preliminary results from recombination analysis involving several mutants indicate that the thialysine-resistant mutations are not linked to each other and that more than one gene is likely to be responsible for thialysine resistance.

Different activities of lysyl-tRNA synthetase were present in different mutants. Several mutants showed less than $50 \%$ of the wild-type activity. These differences in activity suggest that the selected mutants have undergone different mutations either in the same gene or in different genes which affect the synthesis or the activity of lysyl-tRNA synthetase. Hirschfield \& Zamechnik (1971) have reported thialysine-resistant mutants of $E$. coli with 5 to $50 \%$ of the wild-type lysyl-tRNA synthetase activity. In bacteria, only one lysyl-tRNA synthetase is known and this activity from $E$. coli is inhibited by thialysine (Stern \& Mehler, 1965). Genetic and regulatory properties of lysyl-tRNA synthetase of $S$. cerevisiae are not known (Rymo et al., 1972).

Thialysine-resistant mutants in bacteria elicit pleiotropic effects including alteration of the quality (feedback sensitivity) and the quantity (repressibility) of specific biosynthetic enzymes as well as the impairment of lysyl-tRNA synthetase activity (Hirschfield \& Zamechnik, 1971; Coles \& Brenchley, 1976). The role of tRNA synthetase mutations on the derepression of biosynthetic enzymes is well known in bacteria (Neidhardt et al., 1975). A derepression of the isoleucine, methionine and threonine biosynthetic enzymes in their corresponding tRNA synthetase mutants is also known in S. cerevisiae (McLaughlin et al., 1969; Nass \& Hasenbank, 1970; Cherest et al., 1975). Such a derepression of biosynthetic enzymes coupled with the feedback insensitivity of homocitrate synthase (Gray \& Bhattacharjee, 1976; Heslot et al., 1979) would explain the increased production and excretion of lysine in specific mutants. Results from the studies on dominance, recombination, temperature sensitivity and lysyl-tRNA synthetase activity suggest that more than one (possibly three) nuclear gene is involved in the determination of thialysine resistance and lysyl-tRNA synthetase activity in $S$. cerevisiae. 
This research was supported by the faculty research committee, Miami University and by grants BMS75-07208 and PCM78-24863 from the National Science Foundation, U.S.A.

\section{REFERENCES}

Bhattacharjee, J. K. \& Sinha, A. K. (1972). Relationship among the genes, enzymes, and intermediates of the biosynthetic pathway of lysine in Saccharomyces. Molecular and General Genetics 115, 26-30.

Broquist, H. P. \& Trupin, J. S. (1966). Amino acids metabolism. Annual Review of Biochemistry 35. 231-274.

Cherest, H., Kerjan, S. Y. \& DE RobichonSzulmajster, H. (1975). Methionine- and $S$ adenosyl-methionine-mediated repression in a methionyl-transfer ribonucleic acid synthase mutant of Saccharomyces cerevisiae. Journal of Bacteriology 123, 428-435.

Coles, F. T. \& Brenchley, J. E. (1976). Inhibition of growth and aspartokinase activity of Salmonella typhimurium by thialysine. Biochimica et biophysica acta 428, 647-655.

Delforge, J., Messenguy, F. \& Wiame, J. M. (1975). The regulation of arginine biosynthesis in Saccharomyces cerevisiae. The specificity of $\arg R$ mutations and the general control of amino acid biosynthesis. European Journal of Biochemistry 57, 231-239.

Freidrich, C. G. \& Demain, A. L. (1977). Effects of lysine analogues on Penicillium chrysogenum. Applied and Environmental Microbiology 34, 706-709.

Gornall, A. G., Bardawill, C. J. \& David, M. M. (1949). Determination of serum protein by means of the biuret reaction. Journal of Biological Chemistry 177, 751-766.

Gray, G. S. \& Bhattacharjee, J. K. (1976). Biosynthesis of lysine in Saccharomyces cerevisiae: regulation of homocitrate synthase in analogueresistant mutants. Journal of General Microbiology 97, 117-120.

GreER, H. \& FINK, G. R. (1976). Isolation of regulatory mutants in Saccharomyces cerevisiae. Methods in Cell Biology 11, 247-271.

Haidaris, C. G. \& BhattacharJee, J. K. (1978). Lysine production by thialysine-resistant mutants of Saccharomyces cerevisiae. Journal of Fermentation Technology 56, 189-192.

Heslot, H., Gaillardin, C., Beckerich, J. M. \& FourNIER, P. (1979). Control of lysine metabolism in the petroleum yeast Saccharomycopsis lipolytica. In Genetics of Industrial Microorganisms, pp. 54-60. Edited by O. K. Sebek \& A. I. Laskin. Washington, D.C.: American Society for Microbiology.

HirschField, N. I. \& Zamechnik, C. P. (1971). Thiosine-resistant mutants of Escherichia coli K-12 with growth-medium-dependent lysyl-tRNA synthase activity. I. Isolation and physiological characterization. Biochimica et biophysica acta 259 , $330-340$.

HUtTER, R. (1979). Regulation of primary metabolism. In Genetics of Industrial Microorganisms, pp. 4453. Edited by O. K. Sebek \& A. I. Laskin. Washington, D.C.: American Society for Microbiology.
Jegede, V. J., Spender, F. \& Brenchley, J. E. (1976). Thialysine-resistant mutants of Salmonella typhimurium with a lesion in the thrA gene. Genetics 83, 619-632.

Kinzel, J. J. \& Bhatt AcharjeE, J. K. (1979). Role of pipecolic acid in the biosynthesis of lysine in Rhodotorula glutinis. Journal of Bacteriology 138 , $410-417$.

Lindegren, C. C. (1953). Gene conversion in Saccharomyces. Journal of Genetics 51, 625-637.

McClary, D. O., Nutley, W. L. \& Miller, G. P. (1959). Effect of potassium versus sodium in the sporulation of Saccharomyces. Journal of Bacterio$\log y$ 78, 362-367.

Mclaughlin, S. C., Magee, P. T. \& Hartwell, H. L. (1969). Role of isoleucyl-transfer ribonucleic acid synthetase in ribonucleic acid synthesis and enzyme repression in yeast. Journal of Bacteriology 100 . 579-584.

Mortimer, R. K. \& Hawthorne, D. C. (1976). Grenetic mapping in yeast. Methods in Cell Biology 11, 221-232.

NASS, G. \& HaSEnBank, R. (1970). Effect of borrelidin on the threonyl-tRNA synthetase activity and the regulation of threonine biosynthetic enzymes in Saccharomyces cerevisiae. Molecular and General Genetics 108, 28-32.

Neidhardt, F. C., Parker, J. \& McKeever, W. G. (1975). Function and regulation of aminoacyl-tRNA synthase in prokaryotic and eucaryotic cells. Annual Review of Microbiology 29, 215-250.

RYMo, L., Lundvik, L. \& LAGerkvist, V. (1972). Subunit structure and binding properties of three amino acid transfer ribonucleic acid ligases. Journal of Biological Chemistry 247, 3888-3899.

SANO, K. \& SHIIO, I. (1970). Microbial production of L-lysine III. Production by mutants resistant to $S$-(2-aminoethyl)-L-cysteine. Journal of General and Applied Microbiology 16, 373-391.

Sherman, F. \& LAwrence, C. W. (1974). Saccharomyces. In Handbook of Genetics. vol. 1, pp. 359-393. Edited by R. C. King. New York: Plenum Press.

Stern, R. \& MEhleR, A. H. (1965). Lysyl-sRNA synthase from Escherichia coli. Biochemische Zeitschrift 342, 400-409.

Takenouchi, E., Nikuloua, D. K., Awano, K., SODA, K. \& TANAKA, H. (1977). Excretion of lysine by lysine sulfur analogue resistant-mutants of Candida pelliculosa. Agricultural and Biological Chemistry 41, 615-616.

UMBARGER, H. E. (1971). Metabolite analogues as genetic and biochemical probes. Advances in Genetics 15, 119-136.

Vold, B., Szulmajster, J. \& Carbone, A. (1975). Regulation of dihydrodipicolinate synthase and aspartate kinase in Bacillus subtilis. Journal of Bacteriology 121, 970-974. 